\title{
Comparison of Two Different Yarn Evenness Test Methods
}

\author{
Dairong Zhang \& Ling Cheng \\ College of Textiles, Tianjin Polytechnic University, Tianjin 300160, China \\ E-mail: happy_being@yahoo.cn
}

\begin{abstract}
The evenness of yarn is an important index of quality control of textiles, so the researches about the yarn evenness test method have been the hotspot in the textile measurement for recent years. In this article, two main yarn evenness testing methods including the Uster method and the CTT (Constant Tension Transport) method which are important in the present textile industry are compared and studied. Though comparing and analyzing the testing principles of two methods, adopting the method of statistical analysis to correlatively analyze the testing data obtaining from two different testing measures, the method of CTT can more visually and exactly describe the appearance quality of yarns.
\end{abstract}

Keywords: Yarn evenness, CTT, Uster, Value of CV

The evenness of yarn is one of main indexes to measure the quality of yearns. The unevenness of yarns will deteriorate the mightiness of yarns, and increase the end breakage rate in the spinning, and the increase of the end breakage rate will directly limit the speed of the machines and reduce the productivity. In addition, the unevenness of yarns will seriously influence the appearance quality of textiles.

The usual yarn evenness testing methods mainly include the length measurement and weight measurement method, the visual measurement method and the Uster evenness tester method. Because of large computation, the length measurement and weight measurement method is only used in the research works requiring higher nicety or adjusting and measuring unevenness instruments, and it is rarely adopted in general tests. Because the visual measurement method is quick and convenient, and it can comprehensively evaluate the appearance quality of yarns, and it is a very usual method in productions, but it has many deficiencies such as large man-made factor influences, random character, non-objectivity and bad repetition character, and its testing results are hard to be reserved. So the application range of above two testing methods will be narrower and narrower, and they will be finally replaced by other testing methods. The Uster evenness tester can get rid of the influence of man-made factors to the testing results, and it can quickly and objectively measure the unevenness of yarns, so it is applied widely. However, as viewed from its testing principle, it still has certain deficiencies. First, the Uster CV value of yarn evenness can only denote the unevenness degree of yarns, but can not reflect the uneven structure of yarns. Second, the Uster CV value of yarn evenness only considers the average of the unevenness degree of yarns, and can not reflect the uneven waves with different characters on yarns, i.e. it ignores the discrete character of yarn unevenness. But these uneven waves of yarns would largely influence the unevenness of cloth cover. Third, when measuring blended yarns, because both the properties of fiber materials and the dielectric coefficients are different, and if the blended evenness of fibers in yarns is bad, the capacitance will change, which will influence the $\mathrm{CV}$ values. If above factors can not be controlled effectively, the nicety of the testing result of yarn unevenness will be influenced. Fourth, the nicety of testing values will be impacted by the testing conditions (the atmosphere state, the historical reversion condition of samples, the time of humidifying treatment) (Lu, 2008).

At present, with the development of the computer and the image processing technology, people begin to utilize the computer visual technology to evaluate the appearance quality of yarns, and obtained large achievements. For example, combining with the technologies of optics and computer image processing, scientists can acquire images of yarns by the knowledge of applied mathematics such as the wavelet analysis, and implement image processing by pre-compiled computer software to obtain the fineness unevenness of yarns and the blending ratio of hairiness, the unevenness rate of blended yarns and other quality indexes (Wang, 1999, P.101-103). And the CTT yarn performance tester made by American Lawson-Hemphill Company to evaluate the comprehensive performance of yarns is the most representative one. This machine adopts advanced CCD digital imaging technology to test the appearance quality of yarns, such as the diameter of yarns, the appearance and outline changes of yarns, the faults of yarns and the hairiness. Because it adopted completely different testing principle, it is valuable to study and discuss the similarities and differences about the appearance quality of yarns.

The experiment method will be used to compare two testing methods including Uster and CTT, and both differences and relationship will be analyzed, which can be used as references to more objectively evaluate the appearance quality of yarns. 


\section{Comparison of the testing principles of two methods}

\subsection{Testing principle of the Uster yarn evenness tester}

The Uster yarn evenness tester is the instrument developed by Switzerland Uster Company, and it is used to test the evenness of yarns, and there are many types and kinds. This evenness tester uses the capacitance conversion principle to translate the non-electric yarn section change into the electric singles representing the change of section. The testing part is composed by the capacitors with two parallel metal plates. Because the dielectric coefficient of the fiber materials exceeds the dielectric coefficient of air, when the sample of yarn enters into the capacitor with certain speed, the capacitance of the polar plate will increase, and the change of the capacitance is related with the actual volume of the yarns in the polar plates. Supposed that the polar plates with experiment materials is a capacitor composed by multi-layer mediums, when the yarns enters, the relative change of the capacitance of the capacitor is

$$
\frac{\Delta C}{C_{0}}=\frac{\varepsilon-1}{1+\varepsilon\left(\frac{1}{\lambda}-1\right)}
$$

Where, $\mathrm{C}_{0}$ is the capacitance of the parallel plate capacitor before the yarns enter, $\varepsilon$ is the dielectric coefficient of the sample, $\lambda=\frac{d}{D}$ is the fullness of the capacitor, $\mathrm{d}$ is the depth of the sample, and $\mathrm{D}$ is the space between polar plates.

The dielectric coefficient of the sample $\varepsilon$ changes with the humidity of the materials, and when the fullness $\lambda$ is small, the relationship between the capacitance relative change and the dielectric coefficient of the sample is not obvious, so when $\varepsilon » 1$ and $\lambda \ll 1$, the relative change of capacitance $\frac{\Delta C}{C_{0}}=\lambda$. Under this condition, the relative change of capacitance is not correlative with the dielectric coefficient of the sample, and the testing result shows that the signals is positive proportional with the volume or weight of the samples in the polar plates. When the fullness exceeds $20 \%$, the linear relationship between the capacitance relative change and the dielectric coefficient will be destroyed, and it will impacted by the humidity. When the Uster evenness tester is used, to ensure the linear relationship between the capacitance relative change and the dielectric coefficient, the fullness should be small as possible, but too small fullness will impact the sensitivity of the testing. Therefore, multiple measurement troughs are designed in the Uster evenness tester for yearns with different thicknesses, and the regulation should be strictly followed when using it. The measurement result of the capacitance method only represents the total volume or weight of the yarns within the length of polar plate, not the change of the thicknesses of the yarns in the polar plate. The length of the capacitance polar plate will influence the measurement results of the period unevenness and random unevenness, and when the polar plate of $8 \mathrm{~mm}$ and the average length of fibers exceed $25 \mathrm{~mm}$, the influences can be ignored. The electric field distribution of the polar plate capacitor is very complex, and the shielding protection loop will produce the distribution capacitance to make the electric lines to present non-parallel distribution, and the reverse region of the electric lines exists, so the yarns must be passed in proper regions, and the measurement values will be stable. Because of the anisotropy of textile fibers, the capacitance change is related with the weight of the yarns, and impacted by the section formation and structure, so the formation of yarns should be unchangeable when testing (Zhang, 2005, P. 1-3). In a word, the Uster evenness tester is to measure the average value of the volumes or weights of a segment of yarns in the measurement area.

\subsection{Testing principle of CTT}

CTT yarn performance tester is made by the American Lawson-Hemphill Company, and it can measure various performances of yarns under dynamic conditions. The Yarn Analysis System (YAS) in the instrument can comprehensively test and analyze the indexes of appearance quality of yarns.

The YAS is composed by the host computer of CTT, the accessory set of yarn appearance quality test, and a set of corresponding data processing software. Figure 1 is the working principle of YAS, and it includes the linear scanning camera, the illumination system, the CTT yarn supply system of constant tension and the computer which is used for the data acquirement and data processing.

Yarns passes a digital camera by the normal testing speed of $100 \mathrm{~m} / \mathrm{min}$, and the digital system is composed by CDD cameras with higher distinguish-ability $\left(3.5 \times 10^{-3} \mathrm{~mm}\right)$, and the yarn diameter of 0.55 will be measured exactly, and the blur images will not exist in the yarns moving with high speed. Though the data processing of computer, relative data of yarn appearance will be generated, and the testing principle is seen in Figure 2, where, the beam of the lamp-house shoots to the photoelectric component 2, and the yarn 3 in movement will form a shadow in the photoelectric component 2, and the light quantity accepted by the photoelectric component and the current quantity in the electric circuit will change with the fineness of yarns, and the fluctuation of the current will be amplified by the amplifier and recorded. The testing result of the CTT yarn testing system will not be impacted by the relative humidity, the color, and 
the blending ratio. And it can find out the faults with the length of $0.5 \mathrm{~mm}$ and the diameter of $3.5 \times 10^{-3} \mathrm{~mm}$, which is the highest level in all testing methods (Lian, 2002). In a word, the CTT is to test the diameter variance of yarns on certain projection face.

\section{Comparison of the testing results of two methods}

The Uster II yarn evenness tester and the CTT yarn performance tester made by American Lawson-Hemphill Company are respectively used to test the evenness of yarns in the article.

\subsection{Materials and testing conditions}

\subsubsection{Materials}

The materials used in the article are 60 kinds of ring-spinning combing senior cotton yarns from 44 domestic enterprises.

\subsubsection{Testing conditions}

Testing temperature: $20^{\circ} \mathrm{C}$;

Relative humidity: $65 \%$;

Initial tension of CTT testing: $1 \mathrm{cN} / \mathrm{t}$

Testing speed of CTT: $100 \mathrm{~m} / \mathrm{min}$;

Testing speed of Uster evenness: $30 \mathrm{~m} / \mathrm{min}$.

\subsection{Testing results}

Table 1 shows the CV values of evenness of 60 kinds of cotton yarns tested by the Uster II yarn evenness tester and the CTT yarn performance tester.

\section{Analysis of results}

\subsection{Relationship of yarn CV values obtained by Uster and CTT}

By the statistical analysis of CV values obtained by two testing methods in Table 1, the average values and standard deviations of $\mathrm{CV}$ values of cotton yarns with various different fineness degrees can be obtained, and the results are seen in Table 2.

From Table 2, to the yarns with different finenesses, the testing result of CTT is bigger than the result of Uster, and the standard deviation is bigger than the SD of Uster. For different kinds of yarns, the CV values obtained by Uster may be almost same, but the measurement results obtained by CTT will be different obviously, which indicates the test of CTT is more sensitive than Uster, and it can more strictly control the evenness of yarns. The correlation relationship between both methods is seen in Table 2, and the correlative coefficient $\mathrm{R}$ is in 0.483-0.761, which shows both methods have certain relativity (Wang, 1986).

\subsection{Yarn basic performance of the relationship of $C V$ values obtained by two different methods}

The statistical analysis method is used to compare and analyze the relationship between the CV values obtained from two different methods with the basic performance of yarns. The comparison result is seen in Table 3 .

From Table 3, the hairiness and the diameter of yarns have certain relativity with the CV values measured by CTT, and the CV values measured by Uster have certain relativity with the diameters of yarns, not the hairiness of yarns. With the increases of the yarn diameter and the hairiness index, the CV values measured by CTT will increase, which accords with actual situation. At the same time, the twist of yarns has certain relativity with the CV values measured by Uster, and it has a little relativity with the CV values measured by CTT, and presents negative relativity, which because that the testing principles of two testing methods are different. Because the CV values of Uster reflect the amount of fibers in the yarn section, and the CTT reflects the projection of yarn diameter, so the increase of yarn diameter and the hairiness will expose more deficiencies of yarns, and deteriorate the performances of yarns, but the CV values measured by Uster can not reflect these changes, which indicate that the CTT evenness tester can more exactly describe the basic performances of yarns than the Uster evenness tester.

\section{Conclusions}

(1) CV values measured by Uster and CTT have certain relativity, and the concrete relationships are different because of the different finenesses of yarns.

(2) The control of CTT to yarn evenness is stronger than the Uster tester, and the sensitivity of CTT to the yarn unevenness is better than the Uster tester.

(3) Comparing with CTT tester, the Uster tester can more easily cover many deficiencies of yarns, and CTT tester can more scientifically and exactly describe the basic performances of yarns. 


\section{References}

Lian, Jun, Wang, Jing \& Lu, Zhong. (2002). A New Measuring Method of Yarn Appearance Quality. Shanghai Textile Science \& Technology. No. 5.

Lu, Jianfeng \& Zhang, Yixin. (2008). Research on Inspecting Methods of Yarn Evenness. Beijing Textile. No. 3.

Wang, Caixia. (1999). Application of Image Processing Technology in the Textile Measurement. Journal of Qingdao University. No. 14(3). P.101-103.

Wang, Rongxin. (1986). Mathematical Statistics. Xi'an: Xi'an Jiaotong University Press.

Zhang, Xichang \& Zhang, Haixia. (2005). Comparison between Capacitive and Photoelectric Yarn Unevenness Testing Methods. Journal of Henan Textile College. No. 17(2). P. 1-3.

Table 1. Testing results of yarn CV values

\begin{tabular}{|c|c|c|c|c|c|c|}
\hline $\begin{array}{l}\text { No. of } \\
\text { yarn }\end{array}$ & $\begin{array}{l}\text { Fineness } \\
\quad(\text { tex })\end{array}$ & $\begin{array}{c}\text { Average } \\
\text { diameter } \\
(\mathrm{mm})\end{array}$ & $\begin{array}{l}\text { Twist (number } \\
\text { of turns } / 10 \mathrm{~cm} \text { ) }\end{array}$ & $\begin{array}{l}\text { Hairiness } \\
\text { index } \\
(/ 10 \mathrm{~cm})\end{array}$ & $\begin{array}{c}\text { CV of } \\
\text { Uster } \\
\text { testing }(\%)\end{array}$ & $\begin{array}{c}\text { CV of } \\
\text { CTT } \\
\text { testing }(\%)\end{array}$ \\
\hline 1 & 18.222 & 0.205 & 84.86 & 97 & 12.30 & 19.60 \\
\hline 2 & 18.222 & 0.196 & 85.28 & 25 & 11.61 & 15.81 \\
\hline 3 & 18.222 & 0.212 & 87.39 & 58 & 13.16 & 19.3 \\
\hline 4 & 18.222 & 0.174 & 89.96 & 31 & 11.95 & 15.51 \\
\hline 5 & 18.222 & 0.184 & 76.41 & 25 & 11.29 & 14.43 \\
\hline 6 & 18.222 & 0.195 & 83.57 & 44 & 13.72 & 19.53 \\
\hline 7 & 18.222 & 0.192 & 93.39 & 58 & 12.01 & 15.85 \\
\hline 8 & 18.222 & 0.189 & 84.03 & 119 & 10.85 & 15.68 \\
\hline 9 & 18.222 & 0.203 & 77.79 & 30 & 11.61 & 19.20 \\
\hline 10 & 18.222 & 0.183 & 71.80 & 37 & 12.16 & 14.63 \\
\hline 11 & 18.222 & 0.180 & 81.42 & 13 & 10.04 & 10.79 \\
\hline 12 & 18.222 & 0.189 & 91.17 & 41 & 11.72 & 16.12 \\
\hline 13 & 18.222 & 0.191 & 85.15 & 37 & 11.42 & 17.39 \\
\hline 14 & 18.222 & 0.189 & 81.35 & 73 & 11.24 & 14.12 \\
\hline 15 & 14.578 & 0.163 & 96.26 & 45 & 10.75 & 13.86 \\
\hline 16 & 14.578 & 0.162 & 91.01 & 31 & 11.52 & 15.57 \\
\hline 17 & 14.578 & 0.171 & 93.21 & 67 & 12.95 & 17.39 \\
\hline 18 & 14.578 & 0.167 & 94.21 & 59 & 12.76 & 16.65 \\
\hline 19 & 14.578 & 0.175 & 99.55 & 55 & 14.11 & 19.43 \\
\hline 20 & 14.578 & 0.171 & 92.60 & 35 & 11.96 & 18.39 \\
\hline 21 & 14.578 & 0.158 & 81.91 & 18 & 11.70 & 12.20 \\
\hline 22 & 14.578 & 0.176 & 96.34 & 46 & 13.04 & 16.89 \\
\hline 23 & 14.578 & 0.160 & 93.64 & 24 & 11.82 & 14.59 \\
\hline 24 & 14.578 & 0.166 & 96.41 & 92 & 12.62 & 16.28 \\
\hline 25 & 14.578 & 0.171 & 90.94 & 26 & 12.93 & 16.69 \\
\hline 26 & 14.578 & 0.165 & 92.77 & 48 & 12.48 & 16.12 \\
\hline 27 & 14.578 & 0.177 & 94.05 & 61 & 12.10 & 16.44 \\
\hline 28 & 14.578 & 0.167 & 94.59 & 1 & 13.01 & 16.72 \\
\hline 29 & 14.578 & 0.179 & 82.21 & 41 & 12.48 & 18.30 \\
\hline 30 & 14.578 & 0.164 & 95.69 & 25 & 11.71 & 14.09 \\
\hline 31 & 14.578 & 0.161 & 97.83 & 55 & 12.66 & 15.92 \\
\hline
\end{tabular}




\begin{tabular}{|c|c|c|c|c|c|c|}
\hline 32 & 14.578 & 0.162 & 88.70 & 30 & 11.12 & 14.37 \\
\hline 33 & 14.578 & 0.157 & 93.47 & 20 & 11.28 & 14.44 \\
\hline 34 & 9.718 & 0.122 & 117.02 & 15 & 13.25 & 14.46 \\
\hline 35 & 9.718 & 0.126 & 128.37 & 26 & 12.48 & 15.97 \\
\hline 36 & 9.718 & 0.127 & 105.69 & 9 & 11.92 & 12.86 \\
\hline 37 & 9.718 & 0.123 & 121.95 & 23 & 12.39 & 15.36 \\
\hline 38 & 9.718 & 0.130 & 108.56 & 19 & 12.68 & 13.96 \\
\hline 39 & 9.718 & 0.132 & 118.61 & 24 & 13.19 & 14.78 \\
\hline 40 & 9.718 & 0.128 & 107.07 & 13 & 13.33 & 14.34 \\
\hline 41 & 9.718 & 0.140 & 116.17 & 29 & 14.84 & 18.23 \\
\hline 42 & 9.718 & 0.120 & 119.73 & 5 & 12.11 & 13.31 \\
\hline 43 & 9.718 & 0.122 & 139.63 & 20 & 12.65 & 12.90 \\
\hline 44 & 9.718 & 0.128 & 108.87 & 8 & 13.34 & 14.50 \\
\hline 45 & 9.718 & 0.119 & 118.53 & 11 & 12.08 & 14.72 \\
\hline 46 & 9.718 & 0.131 & 120.64 & 40 & 11.19 & 15.68 \\
\hline 47 & 11.662 & 0.139 & 114.18 & 10 & 12.69 & 13.86 \\
\hline 48 & 11.662 & 0.136 & 112.01 & 13 & 11.96 & 13.24 \\
\hline 49 & 11.662 & 0.137 & 105.61 & 9 & 13.23 & 13.68 \\
\hline 50 & 11.662 & 0.134 & 92.13 & 3 & 11.00 & 12.30 \\
\hline 51 & 11.662 & 0.142 & 106.45 & 23 & 12.23 & 15.01 \\
\hline 52 & 7.229 & 0.111 & 136.46 & 37 & 13.71 & 15.68 \\
\hline 53 & 7.229 & 0.110 & 138.90 & 25 & 13.52 & 15.86 \\
\hline 54 & 7.229 & 0.109 & 146.99 & 2 & 13.84 & 13.96 \\
\hline 55 & 7.229 & 0.108 & 140.43 & 15 & 14.32 & 15.92 \\
\hline 56 & 7.229 & 0.108 & 132.02 & 30 & 13.17 & 15.31 \\
\hline 57 & 7.229 & 0.102 & 163.09 & 6 & 13.76 & 14.85 \\
\hline 58 & 7.229 & 0.106 & 141.38 & 1 & 13.15 & 13.63 \\
\hline 59 & 7.229 & 0.109 & 135.92 & 27 & 14.33 & 16.82 \\
\hline 60 & 7.229 & 0.104 & 154.19 & 18 & 13.81 & 14.91 \\
\hline
\end{tabular}

Note: Because the recognized harmful hairiness index length of cotton yarn is $3 \mathrm{~mm}$, the selected hairiness index length when using CTT to test the hairiness index is $2.678 \mathrm{~mm}$. The so-called hairiness index means the statistics of hairiness amount exceeding certain initialized length value on the single side of yarn in the unit length yarn. 
Table 2. Statistical results of two different instruments testing same yarn evenness CV value

\begin{tabular}{|c|c|c|c|c|c|}
\hline $\begin{array}{c}\text { Fineness of } \\
\text { yarn } / \text { tex }\end{array}$ & $\begin{array}{c}\text { Testing } \\
\text { instrument }\end{array}$ & $\begin{array}{c}\text { Average } \\
/ \%\end{array}$ & $\mathrm{SD}$ & $\begin{array}{c}\text { Relativity of two CV } \\
\text { values }\end{array}$ & $\begin{array}{c}\text { Correlative } \\
\text { coefficient of two } \mathrm{CV} \\
\text { values }\end{array}$ \\
\hline \multirow{2}{*}{18.222} & CTT & 16.283 & 2.524 & \multirow{2}{*}{$Y=2.108 X-8.752$} & \multirow{2}{*}{$\mathrm{R} 1=0.761$} \\
\hline & Uster & 11.791 & 0.911 & & \\
\hline \multirow{2}{*}{14.578} & CTT & 16.018 & 1.781 & \multirow{2}{*}{$Y=1.633 X-4.012$} & \multirow{2}{*}{$\mathrm{R} 2=0.754$} \\
\hline & Uster & 12.263 & 0.822 & & \\
\hline \multirow{2}{*}{11.662} & CTT & 14.698 & 1.438 & \multirow{2}{*}{$Y=0.773 X+4.856$} & \multirow{2}{*}{$\mathrm{R} 3=0.483$} \\
\hline & Uster & 12.727 & 0.899 & & \\
\hline \multirow{2}{*}{9.718} & CTT & 13.618 & 0.985 & \multirow{2}{*}{$Y=0.678 X+5.331$} & \multirow{2}{*}{$\mathrm{R} 4=0.576$} \\
\hline & Uster & 12.222 & 0.836 & & \\
\hline \multirow{2}{*}{7.229} & CTT & 15.216 & 1.002 & \multirow{2}{*}{$Y=1.355 X-3.398$} & \multirow{2}{*}{$\mathrm{R} 5=0.570$} \\
\hline & Uster & 13.734 & 0.422 & & \\
\hline
\end{tabular}

Note: In the list showing the CV value relevance of two testing methods, the testing data of CTT are values of Y, and the testing data of Uster are values of $X$.

Table 3. Correlative coefficients of two CV values and other basic properties of yarns

\begin{tabular}{|c|c|c|}
\hline & CV value of CTT & CV value of Uster \\
\hline Average diameter of yarns & $\mathrm{R} 6=0.462$ & $\mathrm{R} 6,=-0.465$ \\
\hline Hairiness index of yarns & $\mathrm{R} 7=0.517$ & $\mathrm{R} 7,=-0.166$ \\
\hline Twist of yarns & $\mathrm{R} 8=-0.215$ & $\mathrm{R} 8,=0.600$ \\
\hline
\end{tabular}

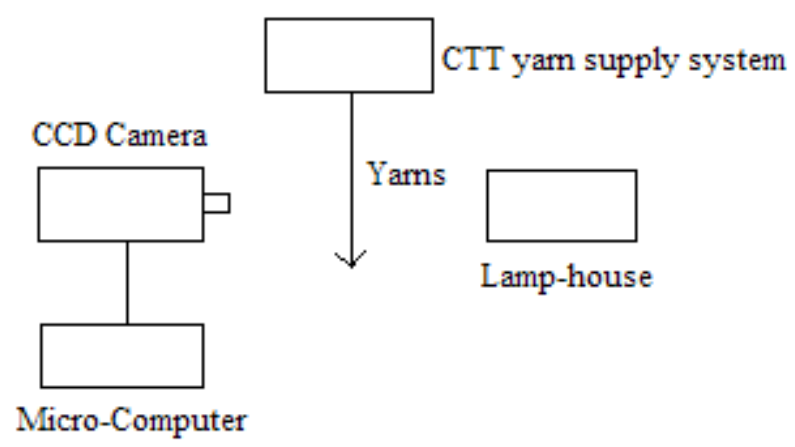

Figure 1. Working Principle of YAS in CTT

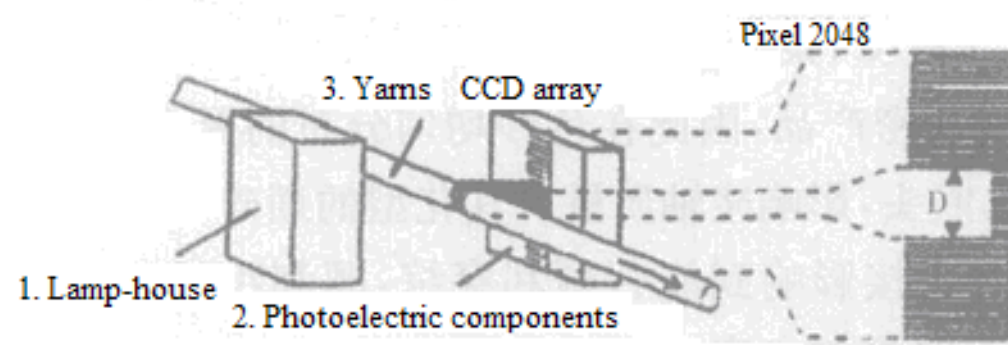

Pixel 1

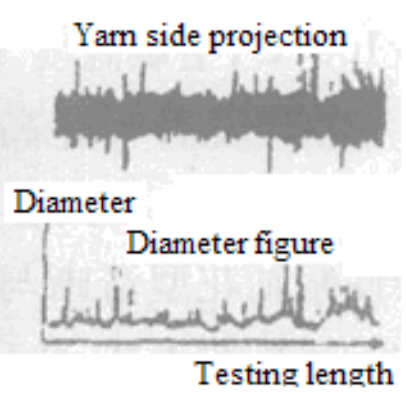

Testing length

Figure 2. Testing Principle of YAS in CTT 